\title{
Log10 Fluorescent Assay Infectious Dose 50 Percent per Dose
}

National Cancer Institute

\section{Source}

National Cancer Institute. Log 10 Fluorescent Assay Infectious Dose 50 Percent per Dose. NCI Thesaurus. Code C68884.

A unit of potency expressed as a decadic log arithm of a of 50 percent infectious dose as defined in the particular fluorescent assay method per dose of preparation. 